\title{
Toward Better Understanding for the So Called "A Fourth Paradigm" in the Arab World: A Multiple Case Study on the Telecoms Sector in Jordan
}

\author{
Naser Khdour \\ Business Administration Department, Philadelphia University, Jordan \\ E-mail:nkhdour@philadelphia.edu.jo \\ Martin Harris \\ School of Business, Essex University, England \\ E-mail: martinh@essex.ac.uk \\ Naser Saif \\ Hospital Management Department, Philadelphia University, Jordan \\ E-mail: nsaif@philadelphia.edu.jo
}

Received: Dec. 28, 2015 Accepted: Feb. 10, $2015 \quad$ Published: April 1, 2015

doi:10.5296/jmr.v7i3.6839 URL: http://dx.doi.org/10.5296/jmr.v7i3.6839

\begin{abstract}
:
This research has alluded to Weirs paper on management in the Arab world as a fourth paradigm that can be seen as distinct from the US, European and Japanese models. Case study investigation is used to explore and elucidate the 'lived experience' of management in these organizations. Weir talks about cultural values and a matrix of belief in behavioral practice and associational norms, also Arab management approach relies on 'networks of relatives and friends' which stimulates the researchers to cover these issues under the social capital umbrella. The interviews material has shown that whilst the idea of a radically discontinuous paradigm shift sits uneasily with the idea of organizationally and culturally hybrid forms of borrowing, it is nevertheless possible to discern a number of ways in which Weir's argument might be nuanced. Social capital would form one dimension of the paradigm;
\end{abstract}




\section{Macrothink}

Journal of Management Research ISSN 1941-899X 2015, Vol. 7, No. 3

Organizational hybridity would represent a second major dimension and neo-tribalism a third whereas relations management would represent a fourth. However, Globalization is considered as an 'external' dimension in which Arab countries are seen to participate in the emerging international division of labour and expertise. The fourth management paradigm was a piece of mosaic; although it includes small pieces of different colours, it is still a distinctive entity in itself.

Keywords: Arab management paradigm, Social Capital, Hybridity, Neo-tribalism, Relations management, Middle East, Jordan 


\section{Introduction:}

The importance of the Arab world in general, as Weir (2001: 2) has pointed out, is that it provides a great deal of the energy that supports developed countries; it provides employment for skilled workers from the West, as well as domestic workers and others from the surrounding region; and it provides quality training from a number of academic institutes which have been steadily growing. However, there is a dearth of serious scholarly accounts of the management structures and the style of business practiced by Arabs (Weir, 2001: 6); and on the whole, it is common to find academics passing disparaging remarks about business in the Arab world (Weir, 2001: 3). With regard to management, an unarticulated assumption has persisted for many years that the foundational theories of management, indeed the very sense of the term 'management', can be unproblematically appealed to and built upon (see Weir, 2001: 7). The most rudimentary assumption was that management refers to the American model of carrying out business (Weir: 2001: 7). Basing their theories on limited examples of how organizations and people solve problems, authors suggested that a universal logic undergirds managerial, as well as personal, decision making (see Weir, 2001: 8). As Weir stated, "These theories form the basic programme of American Business School teaching in the 1950s and 60s. It was taken as read that " management " was American management and that management itself was the American system " (2001: 8).

The ramifications of such a presupposition, of course, could be unfortunate for a culture that does not share the same values as America; and it becomes necessary, furthermore, to cautiously approach the question of managerial hegemony and, by implication, managerial colonialism, by which we mean the suppressive nature of enforcing a managerial model onto a culture, especially a model that is incongruent with the values, structures, or overall outlook of that culture.

While the institutionalized presence of Ango-American schools of management conveys the impression that there is only one correct, scientifically corroborated model of doing business indeed, to the extent that people in developing countries strive to enter these schools, it is possible to approach the status quo model as one style, or, as Weir (2001: 9) puts it, one paradigm of management.

When we look to the underlying paradigm governing the Japanese style of management, we find the reapplication of what were originally Western initiatives, such as 'statistical process control and quality assurance', as well as a number of other developments that run counter to the western model, such as 'lifelong employment, loan capital, long-term thinking, and excessive investment in human capital' (Weir, 2001: 10). Weir has suggested that more basic cultural perspectives may account for managerial differences evidenced in Japanese society, such as the Japanese ideal of achieving victory by and through defeat (Weir, 2001: 10). Furthermore, the Japanese virtues exemplified in traditional literature indicate that reason and self-interest, probably the most important variables in western business and management, should be overcome (Weir, 2001: 11).

A third paradigm is the uniquely European style of management which emerged in the latter part of the 1970's (Weir, 2001: 12). At the same time as European countries were forced to 
give up their colonial grip on African and Asian countries what was a dramatic contraction of their perceived influence over others European management theory unburdened itself of the American model and adopted philosophies of a markedly European cast (ibid). Weir sees in this a post-colonial attempt to reaffirm 'a new cultural imperialism', which was expressed in the idea that Europeans, as members of a culturally diverse and unpredictable continent, were better suited to handle the weltering seas of business (Weir, 2001: 12). Other characterizations of this paradigm include the view that European managers are more open and curious, rooted in a maritime tradition of trade (ibid).

With regard to Arab management, a number of studies suggest that Arab managers, e.g. in Jordan, relate to 'the relevant [managerial] concepts in a similar way to their counterparts in the West' (Weir, 2001: 13). However, we also find that Arab managers supplement what are essentially Anglo-American managerial models with an approach that relies on 'networks of relatives and friends', an expression of what Hofstede calls a 'high context culture' (see Weir, 2001: 14). Business and personal relationships are interconnected in these cultures (ibid).

Which is we should note, a difficult perspective to appreciate coming from an Anglo-American focus on profits and individualism. According to the Arab way of viewing management and business, financial interactions naturally implicate, as well as demand, right behavior, and 'even if the price is right, inappropriate behavior may be sufficient to disqualify the would-be business partner' (Weir, 2001: 15). In view of these findings, Weir proposes that there is a distinctly Arab form of management that is equivalent to a fourth paradigm (Weir, 2001: 14-15). This paradigm is marked by besides those qualities mentioned above, moderateness. Falling roughly in the middle in quantitative measures of individualism/collectivism, masculinity/femininity, and avoidance/tolerance of uncertainty (ibid).

The significant thing about the Arab management paradigm is that it already represents many of the ideals that new management strategies are seeking to assimilate (Weir, 2001: 17). The western paradigm, which implicitly states that good management practices 'produce added shareholder value', has recently introduced what is essentially an Arab emphasis on relationships in marketing (Weir, 2001: 16); and the Western tendency to let ethics fall by the wayside in pursuit of profits has begun to adjust to the Japanese and Arab management models which operate in accordance with wider cultural values. In other respects too, the western paradigm is beginning to accommodate to managerial approaches that avoid downsizing, which demonstrates a growing appreciation for the health of an organization.

Weir talks about cultural values and a matrix of belief in behavioral practice and associational norms, also Arab management approach relies on 'networks of relatives and friends' which stimulates the researchers to cover these issues under the social capital umbrella. The concept of social capital (Coleman, 1988; Nahapiat, 1998, Adler, 2002) refers to associational norms and sociability. But empirical studies show that these factors influenced the development of 'management' as a discrete social activity.

However, the question(s) where the researchers arrived at is, which specific forms of social capital have influenced the development of 'management' as a discrete social activity in 
Jordan?

\section{Study Problem}

There are twenty three Arab States with a combined population of 300 million people. These states show very substantial social, political and institutional diversity. For example, some have monarchies or republics, others have socialist or capitalist states, and some are 'oil rich' other are 'desert poor' societies.

Which management paradigms have been adopted by these societies? In which ways do these reflect the legacies of post colonialism? A study of the 'lived experience' (Weir, 2001) of management in these societies will allow us to investigate the link between belief and social action in the Arab world. Weir (2001) proposed that management styles in the Arab world should be understood as a 'fourth paradigm' (2001: 14-15).

\section{Research aims and objectives}

1- To contribute towards a better understanding of the so- called 'fourth paradigm'.

2- To study the nature of significance of social capital in the two telecom organizations in Jordan.

\section{Research Questions}

1. Which management paradigm has been adopted in Jordan?

2. How this could be understood in terms of social capital?

3. Which specific forms of social capital have influenced the development of 'management' as a discrete social activity in Jordan?

\section{Literature Review}

According to (Lin, 2001), human capital can be defined as 'the value added to a labourer when the labourer acquires knowledge, skills, and other assets useful to the employer or firm in the production and exchange processes' (2001: 9). However, human capital can be measured in relation to key indicators such as the general standards of education, training, and experience within the workforce. Human capital is can also be considered as an added value embedded in the labourers themselves where the investment in such capital is good for both the organisation where the labourers will add value and the labourer gains in form of wages and benefits.

Lin (2001) drew on the work of Bourdieu when he defined culture as 'system of symbolic meaning' wherein particular social practices are reproduced by meanings, and symbols. Theories of cultural capital are also associated with social network theory and with the idea that organizations are heavily dependent on coordinated interaction to achieve collective and individual interests" (Salancike,1995: 348). However, the use of social capital as a concept in social science refers to the seminal works of Coleman (1988), Burt (1992), and Putnam (1993) have played a prominent role in cohering and focusing the efforts of researchers working across the broad spectrum of the social sciences. 


\subsection{The components of social capital}

Nahapiet and Ghoshal (1998) have proposed a tripartite model of social capital. While situating social capital in the benefits provided by networks of relationships, they go further by including in their definition of social capital the assets that accrue or result from the network (1998: 243). The authors proposed three dimensions of social capital: the structural dimension, which includes network configuration, appropriable organization, and the presence or absence of network ties (1998: 244); the relational dimension, which includes "assets created and leveraged through relationships", such as trust, norms, obligations and identification (cf. figure 1 in Nahapiet and Ghoshal, 1998: 251); and the cognitive dimension, which refers to resources that result from sharing the same language, codes, and narratives. Importantly, the authors see all of these various forms of social capital as constituting part of the social structure of a network and as aiding network actors in accomplishing their tasks (1998: 244).

To date, the literature indicates that there is very little agreement as to what specifically constitutes social capital, even if there is widespread agreement concerning its general relevance. This is indicative of the ongoing debate surrounding the conceptualisation of social capital. One of these instructive examples is trust or trustworthiness (see Adler and Kwon, 2002: 26), which has been variously conceived of as a form of social capital (see Coleman, 1988), a motivational source of social capital (Adler and Kwon, 2002: 26), a dimension of social capital (Nahapiet and Ghoshal, 1998) and as social capital itself (Fukuyama, 1995). While it is not our intent to contribute to the theorisation of social capital, implementing the concept requires that we be specific which of its sources, dimensions, or manifestations to consider. In view of its still ongoing conceptualisation, it seems prudent that we embrace the concept at those points where there is most unanimity. Certainly social structure specifically the theories of closure and structural holes and norms e.g. trust and reciprocity are the most salient dimensions of social capital. Other issues to consider, though we need not frame them as aspects of social capital, are ability and the "cognitive dimension" proposed by Nahapiet and Ghoshal (1998).

In economic sociology, interest in social capital arose as research began to adduce the relationships available to an actor as a resource in entrepreneurial activities. Indeed, since its nascence, social capital has been a metaphor (see Burt, 1992) for the inherent value and profitability that derives from knowing the right people. As Burt (1992) stated, "Better connected people enjoy higher returns".

Social capital is not only difficult to define because of its multi-dimensional character definitions are further complicated by the range of levels at which it has been located. Theorists have pointed to the level of the individual, the ethnic group, the community, the informal social group, and the formal organization (see Bankston and Zhou, 2002; Coleman, 1988). There are opposing views on the location of social capital in the literature. Some researchers have argued that social capital is found at the individual level, and others have pointed to the community level. Krishna (2001), for example, has argued that social capital is found at several levels. An individual, for example, has social capital based on their family, 
community, profession, and country, at the same time. Adler and Kwon (2002) agreed with this argument and asserted that the origins of social capital are to be found in the social structure of the society where the individual lives. Consequently, social capital has an individual and a collective aspect (Buys and Bow, 2002; Newton, 1997). Social capital, therefore, belongs to the group and can be used by the group or individuals within the group (Sander, 2002).

\subsection{The location of social capital}

The different levels or locations of social capital produce goods that have been viewed as either a private good or a public good (Paxton, 1999; Aldridge et al. 2002). Bullen and Onyx (1998) was in general agreement with this view and argued that social capital seems to be both a private and a public good. However, the literature reveals a lack of consensus on this issue. Coleman (1988) argued that social capital is a public good, whereas, Fukuyama asserted that it is a private good (Fukuyama, 2001; Fukuyama, 2002). He added that social capital is not a public good but a private good that produces widespread positive and negative goods (Fukuyama, 2002). Dasgupta was in agreement with Fukuyama's view. He stated that'social capital is a private good that is nonetheless pervaded by externalities, both positive and negative' (1999: 325).

\subsection{Some key characteristics of social capital}

Attempts to provide a more precise notion of social capital have resulted in many researchers and theorists putting forward distinctive several types and characteristics of social capital. Authors have noted the distinction between bridging and bonding and cognitive and structural. Although not always called the same thing, the distinction between bridging and bonding (and often linking as well) is common in the literature. Aldridge, et al (2002) provided an explanation of these common types of social capital. Bonding is horizontal, between equals within a community whereas bridging is vertical between communities (Dolfsma and Dannreuther, 2003; Narayan, 2002). Bonding social capital is viewed as localized and found between people who live in the same or neighboring communities, and bridging social capital, refers to individuals and organizations that are more distant Wallis (1998) and Wallis and Crocker et al (1998). According to Anheier and Kendall bridging social capital is connected to 'thin trust', as opposed to the bonding (splitting) social capital of 'thick trust' (Anheier and Kendall, 2002). Social capital has also been seen as having structural and cognitive manifestations of social capital (Uphoff and Wijayaratna, 2000).

\subsection{The causes of social capital}

There is a lack of agreement on the determinants of social capital, and there is a shortage of evidence to support any of the suppositions. Several important studies have suggested that social capital's determinants are the product of cultural evolution (Fukuyama 1995; Putnam et al. 1993). On the other hand, others have claimed that social capital can be created nowadays to support political and economic development (Brown and Ashman, 1996). In a more detailed explanation, Aldridge, et al (2002) have suggested that social capital is determined by history and culture; the nature of social structures; the family; education; the 
built environment; economic inequalities and social class; mobility, and patterns of individual consumption. Pantoja (1999) proposed another group of determinants, including family and kinship connections; wider social networks; political parties; institutional and government policies and the rules and norms that regulate public life; and social norms and values. Many of these claims arise from applied theory and come from research undertaken on other areas, such as, network analysis, civic society, and cultural studies. Pantoja concluded that the findings have questionable validity, even if they are based on empirical research (Pantoja, 1999).

\subsection{Advantages of social capital}

Social capital is important; it is like the glue that holds people in society together and is an investment in interpersonal connections that produce returns like any other tangible forms of capital. One of these returns might be the economic return (Cohen and Prusak, 2001), however, Putnam (1993) in his article 'The Prosperous Community' proposed that the social capital is accumulated by explaining why and how, as follows: Stocks of social capital, such as trust, norms, and networks, tend to be self reinforcing and cumulative. Successful collaboration in one endeavor builds connections and trust. (Putnam, 1983)

The research interest and application of the concept may perhaps suggest the theoretical importance of social capital theory. Existing studies, some researchers have argued, have provided abundant evidence of its occurrence and offered valuable examples of its political, economic and social influence (Fine 1999, Montgomery 2000). However, Aldridge, let al, cautioned that some of the empirical evidence on the importance of social capital for economic and social outcomes needs to be regarded with caution because of the vagueness of the models used to estimate its influence. Without a precise method for measurement it is uncertain how the benefits are discovered and tested. Given the uncertainty of the measurement techniques, it is astonishing that there is little doubt in the literature over the soundness of the claimed benefits of social capital. This is a result of two elements: the inherent appeal of the concept; and the widespread mistaken confidence in measurement methodologies. The majority of benefits described in the literature has not been empirically tested but arise from theoretical extrapolation from other concepts (Aldridge et al, 2002).

It has been argued that social capital is important because of its emphases on the sociological notions of social integration, support and cohesion (Requena, 2003). Indeed, Rothstein (2003) argued that the importance of social capital is that it is able to account for, and investigate both macro structures and micro underlying causal factors in society. On the other hand, the literature identifies social capital as important for the efficient operation of the economy, and a stable liberal democracy (Fukuyama, 2001). Social capital produces a level of cooperation between individuals that cuts across different sectors and power differences (Kenworthy, 1997).

\subsection{Possible disadvantages of social capital}

Social capital also has negative aspects. Indeed, some have argued that the features of the concept that facilitate beneficial outcomes may also produce negative outcomes. Thus, 
economic performance may deteriorate, and prevent social mobility and the social cohesion of communities. Crime levels may increase, and educational achievement levels may fall (Aldridge et al. 2002). The same mechanisms that keep costs down in economic markets can induce negative consequences (Fine, 1999). The social bonds that can generate social capital have the possibility to exclude some individuals (Hunter, 2000). Social capital can limit an individual actions and choices (Wall et al. 1998). Portes and Landolt (1996) was the first to discuss the negative aspects of social capital. Now it is clear that social capital can be both beneficial and unproductive at the same time. These two aspects of social capital shape the structure of our current notion of social capital.

\section{Methodology}

Qualitative research has an inductive outlook on the research and an interpretivist epistemology (Bryman and Bell, 2003). This point indicates that a qualitative research approach is the most suitable approach to aid the researchers in this study, to offer a detailed understanding of the role of social capital in shaping management in Jordan, to obtain an insight into the emergence of specifically 'Arab' approaches to management.

The empirical work for the research is taken from the data obtained from the multiple case studies. The interviews for the case studies were carried out in the two Telecom companies in Jordan. These comprised of Zain and Orange. According to Yin (2003) the multiple case study design depends upon the researchers understanding both the literal and theoretical implications, however, the simplest multiple case study design can be based on two or more case studies.

\subsection{Data Collection}

A qualitative approach is followed throughout this research. The main data collection method was from semi-structured interviews. The semi structured interviews selected are in accord with the nature of qualitative research and involve the various perspectives of 'lived experiences' of the participants' understanding of social capital in Jordan's telecommunications (Bryman and Bell, 2003). In total twenty interviews were carried out in Zain and Orange Company. The interviews were designed to include the three levels of managers, supervisors and employees. The interviews covered the two main departments in the company which are the human resources department and the marketing department. In each department, five interviews were carried out to include one manager, one supervisor and three employees.

\subsection{Case Study Design}

Case study research includes both single and multiple case studies. The use of multiple case studies have increased in frequency in recent years and become more prevalent and preferred; this is also due to the fact that most multiple-case studies designs are stronger than single case designs. Single case designs are vulnerable if only because you will have put "all your eggs in one basket" (Yin, 2003: 53). In contrast, the researchers might reap the benefit of having two or more cases, in this research there are two, depending upon the perceived analytical benefit; moreover, this provides analytic generalization rather than statistical generalization (Yin, 
1989).

\section{Findings from the first case study / Zain Company}

This section explains and answers the research question, which specific forms of social capital have influenced the development of 'management' as a discrete social activity in Jordan?

\subsection{The existence of Networks}

It appears that networks exist within the Zain Company. Employees were addressing Networks as a way of dealing with others, in the interaction between colleagues and in team work. As the work was not isolated from other departments, the idea that organizational work was dependent on contact with other departments made the need for networking vital in the organization and one of the influential factors in building up these networks:

Network is something like a chain. I am here at the core, interacting and working with more than one department. I have about eight departmental divisions with whom I have to communicate within a given time. (C2, M3.M)

To achieve organizational success, there is a real need for trustworthy communication with other divisions, to share and transfer information without barriers and open the channel for more information sharing and coordination both within and without the department. By doing so, the employee looks forward to working as a member of a team. All the employees are vital to performing the work as they have these professional, friendship bonds, thus, employees are trying to be friends with each other more than being just working colleagues and may end up by meeting up after work. The existence of networks is shown in the following extract:

At first when I started working I felt like there was a very closed environment in that everybody seemed to know everybody else and the work went smoothly because of the network. It had to be personal first and then they were going to judge me according to my work.(C2, S6.M)

The focus here is on the second element of social capital which was found to be Trust.

\subsection{Trust in Zain}

Zain is described by a research participant as having a trust environment. Trust has been described as stating the truth; taking honest advice from managers and getting help from colleagues. Moreover, employees have good faith that their colleagues are trustworthy:

I trust everyone unless they prove me wrong. Usually when I talk with any employee, I believe that he is speaking the truth. Our environment is a trustworthy, I found that my manager advises me and tells me things that are important for him. If I am in trouble my colleagues always help me out and I always help them out so it is a trust environment.(C2, E5.H.R)

\subsubsection{Definitions of trust}

In this research, the researchers obtained empirical definitions of trust. These definitions 
came from Zain's participants "lived experience" in their company, also, as long as social capital occurs in the daily life of the organization; these definitions represent how trust is being perceived in the daily life of the organization. Managers, supervisors and employees had linked trust with different issues, these issues varied from being truthful while the employees are dealing with their colleagues, living in the organizational environment without gossiping and talking behind other employee's backs. The dependency on others to help getting things done, to being a normal person without wearing any social masks. The following are the dominant themes that emerged when the participants defined trust. Trust based on deliverable work, sharing and discussing information; believe in the person intention and action and way of thinking.

\subsection{Norms in organizations}

By discussing the Norms in the organization, the researchers are able to shed light on the third elements of social capital to address the first research question; which specific forms of social capital have influenced the development of 'management' as a discrete social activity in Jordan?

\subsubsection{Employees understanding of Norms}

Norms in Zain was found to be the third element of social capital. Employees understand Norms in Zain as sharing the same languages, religion, background which basically comes from the culture. The importance of Norms in Zain has received less attention than the importance of the family environment:

Norms will play only a partial role in the organization, because we have norms about sharing the Arabic Language or that we are Muslims or even that we have the same background or the same culture. I believe that Jordan is an open and free country we have many people from different background and they cope with us, it is not problem. The family environment we have here is covering everything and most important than the norms do as long as we feel that we are a family this will increase the relations and the networks then the trust (C2.E2.M)

\subsubsection{Current status of Norms in Zain}

Norms are in existence in Zain; this existence has been linked to the tribe system in Jordan. Employees in one way or another are interested in knowing the family tree of their colleagues, questions about their town and background are usually discussed. It seems like there is a clannishness effect within the organization there but it does not have a large role in Zain but its existence should be mentioned:

When I think about our norms part of it comes from the tribe system we have in Jordan, in our culture, we are brought up under such norms. I cannot say all of us but most of the people refer back to the family tree, and ask things like where are you from? Who is your grandfather? We come from the same town! I think this is clannishness. (C2.E7.H.R)

However, the dependency on Norms as a social capital component is not that much in evidence, moreover, the role norms have played in Zain is limited: 
Norms like religion, background, Arabic culture, does have an effect but not that much here. In Jordan in general there is no difference between Muslims and christens, to be honest with you I cannot see the norms having much effect in the organization. (C2.E10.H.R)

\section{Finding from the second case study / Orange Company}

\subsection{The existence of Network}

The Network was found to be the first element of social capital that has affected management in the Orange telecom organization. Socializing with other employees is a part of human nature, however, the research participants employed at Orange considered every person in their team as important and vital to them. A strong Network exists in orange as a result of the high-quality relationships that exists between employees. This gradually turns into friendships, where employees share many similar personal views with other employees.

The existence of a Network in the Orange Company can be traced back to the values in the Jordanian society which originates from the dominant Jordanian tribe system. The tribal values were reported to be apparent in the organization:

The organization is run through the Network. It is a strong concept because it is based on the cultural values of the tribe system in Jordan. This is based on a region and a sub region, and which family you come from (C3, S3.M)

The departments at Orange are linked together and complement each other, and this has led to an increase in Networking. The Network has been reported as a connection between employees which introduces employees to other employees, and each employee is introduced to many other employees:

Our organization in the telecom communication industry requires a high level of communication between employees and different departments. Our work does not progress without networking with other people in different departments. So if you work in the human resources department you work for different departments and this gives you direct contact with employees and managers. Communication is by emails, interviews, meetings, and networking (C3.S6.H.R)

\subsection{Trust in Orange}

The interviewed employees at Orange have stated that their encounters with colleagues have provided them with the experience to realize the importance of trust in their work place. They stated that they trust their colleagues. It appears that a high level of trust is in existence in Orange. The research participants have explained their understanding and the existence of trust as a result of the empowerment managers have given to them. Moreover, they have also indicated their familiarity with their colleague's task and that they have shared job details in case they have to cover their colleague's work. There appears to be no hidden information about anyone's work: 
We have trust and this enables information to be shared. This increases when you know another person in a different department and you have a good relationship. As a result of this you trust him more and as a result the sharing of information goes smoothly (C3, S3.M)

\subsubsection{Definitions of Trust}

Trust in an organization has many definitions. The research participants reported a variety of definitions of trust in relation to the Orange Company. Trust has been linked with being transparent with employees and being open with them and Trust for them is a word of mouth and confidentiality when they say something to another colleague. The empirical definitions of trust which emerged from the daily life of the interviewed employees were having relationships without barriers, commitment towards completing work to deadlines and good intention.

\subsection{Norms in Orange}

\subsubsection{Employees understanding of Norms}

In the Orange Company employees showed similar understanding of the concept of Norms. Norms has been linked to the Jordanian culture and to the tradition inside this culture. For Jordanians Norms are about sharing the same background, habits, folklore, Islam as a religion, and the Arabic language:

Norms are about sharing the same background. It is sharing issues between me and you; it is habits, traditions and folklore (C3, M4.H.R)

\subsubsection{Current status of Norms in Orange}

Norms is considered as a third element of social capital. The researchers are seeking to find out about the effect of Norms in an organization; however Norms have not had much influence on the management in Orange. Norms was found to be the third element of social capital that has affected the development of management in the Orange Company.

Many reasons emerged for this ranking. Orange is considered as an international company where they have French and Arab employees. In such an environment the diversity should be respected and according to the huge effects of globalization on business it is difficult for Orange employees to see Norms as having a major effect in this trend. In other words, it is too difficult for them to talk about religion or Arabic as a language. Even though Norms have been linked to religion, but these Norms are not applied in organizations. For this reason no Islamic management style has been applied in Orange. Employees talked in depth about this subject area and pointed out that even though Norms are linked to religion and language the current Norms in Orange derive from Western societies built on rules, procedures and instructions:

Norms don't play a major role in companies. We do not focus on norms. When it comes to work, we do not check if the person is a Muslim or not. Most of my friends here are from England and France. We have a very good relationship that is not based on background or religion, or language (C3, E8.M) 


\section{Discussion}

\subsection{Networks in the two organizations}

Preliminary analysis of the case study findings suggested that networking within these organizations was of prime concern to interview respondents. The emphasis placed on networking originated from a deep belief in the importance of the people within organization and the surrounding business environment.

\subsection{Trust in the two organizations}

The fieldwork and data gathering suggest that high levels of trust exist within each of the two case study organizations. When talking about Trust with the participants the researchers had the impression that Trust was an important concept for them even if they found this difficult to separate from other aspects of daily organizational life. Trust was seen a part of the 'lived experience' of daily life within the organization. A close examination of the interview material in each case produced a series of different definitions and constructions of trust by different employees in each of the case study sites.

One important source of organizational Trust as pointed out in Cohen and Prusak (2001), is the role played by 'Ttrust brokers'. This role helps to spread trust throughout an organization. For example, if you need someone to do a vital and complicated piece of work, you will most likely trust a person that has been recommended by a highly trusted colleague who knows you and your requirements. But if that candidate is too busy to do that work, a recommendation given by another person will take place, and they might say 'I know somebody who would do it well'. This occurs because trust in that person has already been established, and if that person is also busy, another suggestion will be made, and this will continue and the acceptance and generalization of trust will extend from person to person, until a person can be found to undertake the piece of work. In addition, an individual's reputation plays an essential role in assessing particular forms of trustworthiness, particularly in the absence of personal experience.

\subsection{Norms in the two organizations}

Norms in the telecoms companies have been linked and understood as sharing Islam as a religion and Arabic as a language, sharing the same ideas and background which have been shaped by the Jordanian culture, and the traditions, habits and folklore within this culture. Whilst the two preceding research themes (networking and trust) appear as core features of organizational life, it would appear that Arab cultural norms have been supplanted by company policies, formal procedures, and guidelines as seen for example in formalized company code of ethics. According to Weir's (2001) analysis of management in the Arab world, he argues that it is impossible to overlook the central role of Islam as this, 'provides a matrix of belief that is manifested in behavioural practice...' (2001: 17) a nexus of connecting values, and a 'common culture', between members (Weir, 2001: 3) Whereas the western paradigm must pay to achieve a stable culture within the organization, Arab management practices already provided this foundation through Islam. 
The previous discussion leads to an evaluation of which specific form of social capital has influenced the development of 'management' as a discrete social activity in Jordan, in other words, the ranking of the elements of social capital were built in a systematic manner. Employees were reflecting on the ranking of social capital from their lived experience and the current working situation, and this has shown that Network come first then Trust and finally, Norms. The following extracts show this ranking:

Yes it is network, because I have a need to discuss something with the other division to complete my work, and when you have found the answer, you gain the trust because a commitment has taken place. He gave me the result and I trust him more, then the last thing I think about is norms (C3, E10.M)

It seems that having a tribe system makes employees think of, and depend on the Network as a first element:

Because we are a part of the tribal community, Network comes first, then Trust then norms because the Norms are more general (C3,E1.H.R)

Moreover, organization such as Orange has a diverse environment, and it includes Arab and French, Jordanian and Palestinian employees. Employees from the North and the South have noted that Networking was the first element in the ranking list, as noted in this interview statement:

Because we [in Orange] are working and living in an international company, people are Arab and French, Jordanian and Palestinian, you need to focus on your network in order to get your work done. Then you gradually build trust and make your network much stronger. Because we are Muslims here as well we put norms third (C3, S3.M)

It has been recognized that trust builds up over time. Employees depend on their networks to get their jobs done and gradually, over time, trust becomes a natural result of such bonding:

If I talk about trust and networking, trust needs time so it is easy to start networking and then to have an issue about trust. So the ranking will be networking first, then trust and then norms (C3, E8.M)

\subsection{The four pillars of the Arab 'fourth paradigm'}

Depending on the findings it could be argued that the Arab fourth paradigm can be understood to take the form of a diamond. The four sides of this diamond are: social capital, organizational hybridity, tribalism management, and relations management. The fourth management paradigm was a piece of mosaic; although it includes small pieces of different colours, it is still a distinctive entity in itself.

On one side of this diamond, it could be seen that the Arab fourth paradigm has been built on social capital (internally). Social capital was found to be the way Arab people ran their business, specifically in a form of having Network first, then Trust, and then Norms.

From another side it is totally built on the organizational hybridity (externally) where the Arab management is not fully westernised despite the strong initiatives to imitate the West or 
America. Western concepts have been borrowed from experiences, ideas, and styles and have been customised so as to fit their culture. (See Harris,et al (2014) for an authoritative account of the latter).

The third side of this diamond is dominated by the tribalism management which is found to be the basis of social capital and forms the base of the Arab management.

In Zain the impact of the clannishness leads people to stick together, work together and support their manager for particular benefits, because as we have discussed, we have this family background and family way of thinking because we don't think as "me" we think as "us", also the Jordanian culture is dependent on the tribe system. The whole community is built on a tribe system where the connection is between the employees and between their relatives and if I helped you this time, you going to help me next time (C2,S6.M)

The importance of this factor has been recognised by many studies such as Alon, when he stated that the Kinship was the basis of the tribal system. It was likened to the Network in social capital:

Tribal society was organized along the lines of real or imagined kinship and the alliances these could produce, with its own leaders who were able, if necessary, to mobilize their fellow tribesmen into a formidable fighting force (2005:218).

Another study by Alon, (2007) has given a function to tribal behaviour, to be role played as in Gemeinscaft (as is the case when individuals give priority to a large association rather than in their own self interest) and Gesellschaft (which is the contrasted case where an individual gives priority to their self interest rather than to their association. According to Alon:

Tribes play a crucial role in cushioning and smoothing out process of rapid modernisation. By doing so, they help to maintain a sense of close and intimate community (Gemeinschaft)...frequently lost modernised societies (Gesellschaft), and prevent or at least postpone social unrest (2007: 7).

The British empowerment of tribalism helped in the development of this management but in modern direction. The dominance of the paternalistic culture in Jordan has affected the tribalism management to an extent that the manger had obtained power in a way that employees were looking at the CEO as the 'Sheikh of the Tribe' or the CEO as the father. The Jordanian society was described as a collectivist society where people didn't think only about themselves but also considered their group. Their networking helped to think in a tribalistic way which brought certain people around in the organization to guaranteeing their loyalty. This has been discussed as a disadvantage of social capital, having such lobbies inside an organization. Previous sections have made comparisons between the tribe and organization on the one hand and the management style which builds on social capital on the other. Social capital, as a local concept, initially came from the tribal system with certain rules and customs. Social capital builds on the same elements that the tribal system builds on.

The fourth side of this paradigm is that Arabian management is a 'relations management', where it is heavily dependent on personal relations and informal ways of running a business. 
Taking into consideration other factors that affect this paradigm, such as globalisation as an external factor, together with various internal factors, such as the Jordanian conceptualisation of the idea that the West is leading them and that they are the best example of the so called modernity in life and business; this has resulted in the imitation of the West becoming a matter of course and being known as the ' hybridity'. The imitation of the West does not mean that Arabs are following in the Western style geographically. They are looking at the West's theories, schools, thoughts and business models. It is considered to be more suitable for their organizations. If the manager is the person who has the power in the Arab management or is acting as the 'Sheikh' of the organisation, has been satisfied with a certain school of thought, then that particular model might be taken and applied. It was also observed that it was a characteristic of Arab management that there was a high dependency on the manager. This paradigm is not a totally Western one and at the same time is not a purely Arabic one, which makes the 'hybridity' into the external logo of this paradigm. Where Jordan could not compare with Europe, in the area of the management style because of having embraced a 'mix and match' approach from each, in order to make it fit the Jordanian style. Where Jordan telecommunications still looks to the West in the area of management, but still applies it with a Jordanian style.

Previous sections have explained that the Arab fourth paradigm can be understood to take the form of a diamond. Thus, the result of this factor might confirm the result of the previous studies. According to (Prasad, 2003: 32) Postcolonial theory can also be applied as a research tool in non-Western contexts, that is, towards an understanding of non-Western management practices. To explicate, it has been remarked that non-Western management practices have been traditionally evaluated against Western norms, and this has resulted in the wholesale devaluation of non 'standard' practices. Disparity, from this old way of thinking, conceals an immanent fault, a lack, and reflects an outdated cultural inheritance that obstructs the smooth functioning of an organization. What postcolonial theory can elucidate is an ethnocentric disparagement of non-Western styles of management, and with this critical perspective, it is possible to inquire into the potential value of non-traditional (non-colonial) approaches.

Taking into consideration that what has put social capital in the shadow of the whole Middle Eastern Arab fourth management paradigm, is that social capital is tribalistic in nature. The Arab social capital has been built on the tribal system which has extended further than Jordan to include the whole Middle East countries. According to Alon:

Yet it is the tribal character of most Middle Eastern societies that form one of the key features of the region and sets it apart from its peers. This phenomenon and it is implications deserve more attention from scholars (2005: 235).

\section{Conclusion}

This research has investigated the role of social capital in shaping management in the Jordanian telecoms sector. In doing so it has sought to examine the relationship between social capital and the emergence of specifically 'Arab' approaches to management.

Social capital is playing a major role in shaping the practice of management in the Jordanian 
telecoms sector. The case studies provide empirical support for the idea that this is sustained by networking behavior, by relatively high levels of trust and by the existence of shared norms.

The two Jordanian telecoms companies agreed to place the Network as a first specific form of social capital which has affected the development of their management activities as a discrete social activity in Jordan.

Trust has emerged as a second element of social capital. Whilst precise definitions and constructions of trust vary, knowledge sharing, transparency and reciprocity are generalized features of organizational life in this sector.

The existence of shared norms represents a substrate within Jordanian society but the two telecom companies studied appear to have augmented this with highly western forms of substantive and formal rationality and this has fostered a much more inclusive approach in which Arab and non-Arab, Christian and Muslim personnel can mix.

This research has alluded to Weirs paper on management in the Arab world as a fourth paradigm that can be seen as distinct from the US, European and Japanese models. Whilst the idea of a radically discontinuous paradigm shift sits uneasily with the idea of organizationally and culturally hybrid forms of borrowing, it is nevertheless possible to discern a number of ways in which Weir's argument might be nuanced. Social capital would form one dimension of the paradigm; Organizational hybridity would represent a second major dimension and neo-tribalism a third whereas relations management would represent a fourth. However, Globalization is considered as an 'external' dimension in which Arab countries are seen to participate in the emerging international division of labour and expertise (see Zahra (2011) for an authoritative account of the latter).

In 2000 Robert Putnam published 'Bowling Alone', he showed how the United States is experiencing a steep decline in its stocks of social capital as connectivity between individuals communities has atrophied. (Putnam, 2000) This research has drawn on the concept of social capital to show that contrary to some of the more rigid interpretations of post colonial theory (see Prasad (2003) and Spivak (1999) for discussions. Jordanian society is possessed of associational norms that will contribute positively toward its own development.

\section{References}

Adler, Paul S., \& Seok-Woo Kwon. (2002). Social Capital: Prospects For a New Concept.' Academy of Management. The Academy of Management Review, 27, 17-40.

Aldridge, Stephen. Halpern, David, \& Fitzpatrick, Sarah. (2002). Social Capital: A Discussion Paper. London, England: Performance and Innovation Unit.

Anheier, Helmut, \& Kendall, Jeremy. (2002). Interpersonal Trust and Voluntary Associations. British Journal of Sociology, 53, 343-362. http://dx.doi.org/10.1080/0007131022000000545

Bankston, Carl L., \& Zhou, Min. (2002). Social Capital as a Process: The Meanings and 
Problems of a Theoretical Metaphor. Sociological Inquiry, 72, 285-317. http://dx.doi.org/10.1111/1475-682X.00017

Brown, L. David, \& Ashman, Darcy. (1996). Participation, Social Capital, and Intersectoral Problem Solving: African and Asian Cases. World Development, 24, 1467-1479. http://dx.doi.org/10.1016/0305-750X(96)00053-8

Bryman, A., \& Bell, E. (2003). Business research methods. New York: Oxford University Press.

Burt, Ronald. (1992). Structural Holes: The social structure of competition. Cambridge, MA: Harvard university press.

Buys, Laurie, \& Bow, Val. (2002). The impact of privacy on social capital. in Social Change in the 21st Century Conference. Brisbane: QUT.

Bullen, Paul, \& Onyx, Jenny. (1998). Measuring Social Capital in Five Communities in NSW. Pp. 49: Centre for Australian Community Organisations and Management (CACOM) CACOM Working Paper Series (No 41).

Cohen, D., \& Prusak, L. (2001). In good company how social capital makes organizations work, Harvard Business School Press Boston, Massachusetts.

Coleman, J. (1988). Social Capital in the Creation of Human Capital. The American Journal of Sociology, 94, Supplement: Organizations and Institutions: Sociological and Economic Approaches to the Analysis of Social Structure. The University of Chicago Press, S965S120.

Dasgupta, Partha. (1999). Economic Progress and the Idea of Social Capital. in Dasgupta and Serageldin, eds. op. cit. pp. 325-424.

Dolfsma. Wilfred, \& Dannreuther, Charlie. (2003). Subjects and boundaries: Contesting social capital-based policies. Journal of Economic Issues, 37, 405-413.

Fine, Ben. (1999). The Developmental State Is Dead-Long Live Social Capital? Development Change, 30, 1-19.

Fukuyama, Francis. (1995). Trust: the social virtues and the creation of prosperity. London: Hamilton, Hamish.

Fukuyama, Francis. (2001). Social capital, civil society and development. Third World Quarterly, 22, 7-20. http://dx.doi.org/10.1080/713701144

Fukuyama, Francis. (2002). Social capital and development: The coming agenda. SAIS Review, 22, 23-37. http://dx.doi.org/10.1353/sais.2002.0009

Harris, et al. (2014). Unveiling the new coined theme "Management Hybridity": A study in culture borrowing. European Journal of social sciences, 45(2).

Hunter, Boyd. (2000). Social exclusion, social capital and Indigenous Australians: Measuring the social costs of unemployment. Canberra: Centre for Aboriginal Economic Policy Research, ANU. 
Kenworthy, Lane. (1997). Civic Engagement, Social Capital, and Economic Cooperation. $\begin{array}{llll}\text { American } & \text { Behavioral Scientist, } & \text { 645-656. }\end{array}$ http://dx.doi.org/10.1177/0002764297040005010

Krishna, Anirudh. (2001). Moving from the Stock of Social Capital to the Flow of Benefits, The Role of Agency. World Development, 29, 925-943. http://dx.doi.org/10.1016/S0305-750X(01)00020-1

Krishna, Anirudh. and Uphoff, Norman. (2002). 'Mapping and measuring social capital through assessment of collective action to conserve and develop watersheds in Rajasthan, India. in The Role of Social Capital in Development, edited by Thierry Van Bastelaer. Melbourne, Cambridge University Press. http://dx.doi.org/10.1017/CBO9780511492600.005

Lin, Nan. (2001a). Building a Network Theory of Social Capital. Pp. 3-30 in Social capital, theory and research, edited by Ronald Burt. New York, Aldine de Gruyter. http://dx.doi.org/10.1017/CBO9780511815447.002

Montgomery, John. D. (2000). Social capital as a policy resource. Policy Sciences, 33, 227-243. http://dx.doi.org/10.1023/A:1004824302031

Nahapiet, J., \& Ghoshal, S. (1998). Social Capital, Intellectual Capital, and the Organizational Advantage. The Academy of Management Review, 23(2), 242-266.

Narayan, Deepa. (2002). Bonds and bridges, social capital and poverty. in Social Capital and Economic Development, Well-being in Developing Countries, edited by Sunder Ramaswamy. Cheltenham, UK, Edward Elgar.

Newton, Kenneth. (1997). Social Capital and Democracy. American Behavioral Scientist, 40, 575-586. http://dx.doi.org/10.1177/0002764297040005004

Pantoja, E. (1999). Exploring the concept of social capital and its relevance for community based development, the case of mining areas in Orissa, India. South Asia Infrastructure Unit, World Bank.

Paxton, Pamela. (1999). Is social capital declining in the United States? A multiple indicator assessment. The American Journal of Sociology, 105, 88. http://dx.doi.org/10.1086/210268

Portes, Alejandro, and Landolt, Patricia. (1996). The downside of social capital. The American Prospect, 26, 18-23.

Prasad, A. (2003). Postcolonial theory and organizational Analysis, A critical Engagement, Palgrave Macmillan, New York, NY.

Putnam, Robert. D. (1993). The prosperous community, Social capital and public life. The American Prospect, 4.

Putnam, Robert. D. (2000). Bowling alone, the collapse and revival of American community. New York, Simon \& Schuster.

Requena, F. (2003). Social capital, satisfaction and quality of life in the workplace, Social 
Indicators Research, 61, 331-360. http://dx.doi.org/10.1023/A:1021923520951

Rothstein, Bo. (2003). Social capital, economic growth and quality of government, The causal mechanism. New Political Economy, 8, 49-71. http://dx.doi.org/10.1080/1356346032000078723

Salancik,G. R. (1995).Wanted, A Good network theory of organization. Administrative Science Quarterly, 40, 345-349. http://dx.doi.org/10.2307/2393642

Sander, Thomas. H. (2002). Social capital and new urbanism, leading a civic horse to water. National Civic Review, 91, 213-221. http://dx.doi.org/10.1002/ncr.91302

Spivak, G. C. 1999. A critique of postcolonial reason, Toward a history of the vanishing present. Cambridge, MA, Harvard University Press.

Uphoff, Norman, \& C. M. Wijayaratna. (2000). Demonstrated Benefits from Social Capital, The Productivity of Farmer Organizations in Gal Oya, Sri Lanka. World Development, 28, 1875-1890. http://dx.doi.org/10.1016/S0305-750X(00)00063-2

Wallis, Allan. (1998). Social capital and community building.(Building Healthier Communities, Ten Years of Learning).(part 2). National Civic Review, 87, 317-19. http://dx.doi.org/10.1002/ncr.87404

Wallis, Allan, Jarle P. Crocker, \& Bill Schechter. (1998). Social capital and community building, part 1. National Civic Review, 87, 253-72. http://dx.doi.org/10.1002/ncr.87306

Wall, Ellen. Ferrazzi, Gabriele, \& Schryer. Frans. (1998). Getting the goods on social capital. Rural Sociology, 63, 300-322. http://dx.doi.org/10.1111/j.1549-0831.1998.tb00676.x

Weir, D. (2001). Management in the Arab World, A Fourth Paradigm?, paper submitted to EURAM conference, 2 Dec..

Yin, R. K. (2003). Case study research, Design and methods. 3rd eds. London, SAGE Publications.

Yin, R. K. (1989). Case study research, Design and methods. London, Sage.

Zahra, A. Shaker (2011). Doing Research in the (New). Middle East, Sailing with the wind. Academy of management perspectives, 25(4), 6-21. http://dx.doi.org/10.5465/amp.2011.0128 